\title{
CONSTRUCTIVE CONCEPTS FOR REDUCING WEAR CAUSED BY THE FRICTION TORQUE OF HIP IMPLANTS
}

\author{
Simona Mihai ${ }^{1}$ \\ ${ }^{l}$ Ph.D Student, Mechanical Engineering, Valahia University of Targoviste, Romania, mihai.simona@yahoo.com
}

\begin{abstract}
The purpose of this paper is to design the mechanical parts intended to reduce wear caused by the friction torque of orthopedic implants and to present the processing technologies used in their implementation.
\end{abstract}

Keywords: orthopedic implants, biomaterials, wear, manufacturing technologies - $* * *$

\section{INTRODUCTION}

Hip joint replacement surgery is done by replacing the upper part of the femur and the damaged hip bone. The damaged bone and cartilage are replaced with implants made of biocompatible materials.

Implants are designed to operate easily and ensure long term operation. In time, due to cyclic dynamic stresses and complex movements performed in adverse biological environment, the optimal functionality of prostheses is lost, sometimes it is possible for an element to come off the supporting bone and, in the long run, there may appear a wear leading to a dysfunction of the mechanical components.

Among the causes leading to the implants' deterioration there are the result of the complex interactions between the constructions, the patient characteristics and the medical factors related to the surgical act.

The constructive version is the controllable variable, which involves choosing the prosthesis' elements geometry, the materials, the manufacturing processes and the methods of sterilization. The lifestyle of each person is unique and so are the patients' characteristics such as weight, intensity of daily activities or skeletal system condition, which makes them uncontrollable environmental variables [1].

In practice, the development of the prosthetic acetabular component as well as that of the femoral one was based, in terms of material, size and shape, on the fundamental principles of mechanical engineering. The mechanical equivalent of the hip joint is shown in Fig -1 .

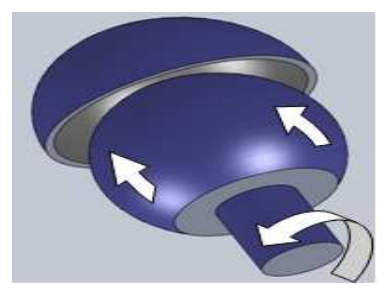

Fig -1: Mechanical equivalent of hip joint

Replacing a natural joint with an artificial one will subsequently affect the load transfer mechanism and will generally be conditioned by it, due to the fact that the components of the prosthesis must allow relative movements specific to the full range of human activities for a long time [1].

2. THE ELEMENTS THAT LEAD TO THE MECHANICAL FRICTION TORQUE ON HIP IMPLANTS

By definition, friction torque is the combination of two or more contact bodies, which are in relative motion of sliding, rolling, pivoting, or a combination of these [2].

Friction torque is the basic element in all tribological analyses. In the hip implants' case, the friction torque occurs between the acetabular cup (Fig -2) and the femoral head (Fig -3).

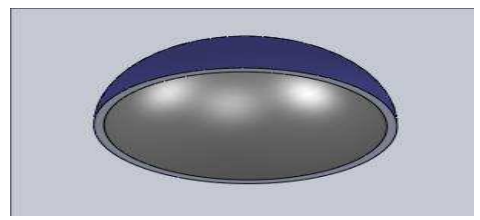

Fig -2: Acetabular cup 


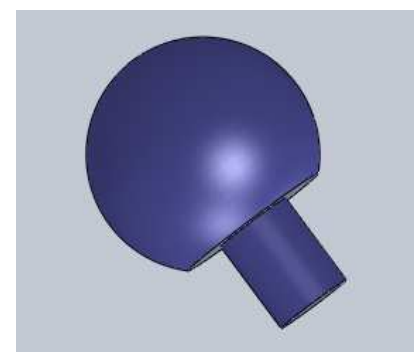

Fig -3: Femoral head

\section{TYPES OF WEAR ON HIP IMPLANTS}

As far as wear types are concerned, the implants removed from patients showed a number of wear mechanisms, as follows: abrasive wear, third body wear, adhesive wear, surface fatigue wear, corrosion wear and fretting wear (Fig 4). Depending on the stresses the implant is subjected to, these mechanisms combine in different times (not all at once), amplifying the wear process.

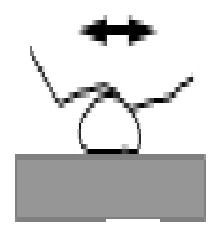

a

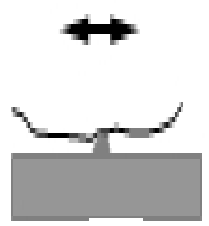

b

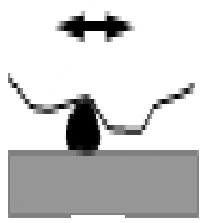

C

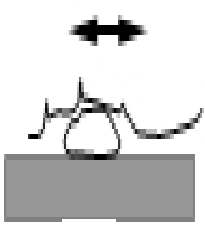

d
Fig- 4: Types of wear

a. adhesive wear; b. abrasive wear;

c. Third body wear;

d. fatigue wear

Adhesive wear (Fig - 4, a) is caused by micro-welding that occurs on the contact between two surfaces in relative motion, so that the strength of the bond is stronger than the resistance force of the material and a small portion of the material is removed from one surface and attached to the other surface.

Adhesive wear may occur immediately by "freezing" or "blocking" elements characterized by relative motion [3].

Abrasive wear (Fig - 4, b.) is caused by hard particles or irregularities that are forced to move against a softer solid material and is a mechanical process which may take particular forms, qualitatively and quantitatively dependent on the shape and quality of the contact surfaces and the mechanical properties of the surface layers.

Third body wear (Fig -4 , c.) is caused by particles of foreign bodies (cement, metal, bone) that are embedded in the joint surfaces. Abrasive wear requires a damage period and a critical hardness value [3].
Fatigue wear (Fig - 4, d.) is a process caused by cyclic mechanical or mechanical-thermal stress associated with a rolling motion, a sliding motion or a combination of both. Fatigue wear is characterized by the occurrence and development of specific micro-craters (cracks below the surface which, in the course of time, removes particles from the surface).

In order to extend the lifetime of hip implants and to improve their tribological performance, in addition to heat treatments and thin-film coating with materials having superior properties, attempts were made to bring in changes in the construction and even the operating principle.

\section{DESIGN OF SOME MECHANICAL ELEMENTS INTENDED TO REDUCE HIP IMPLANTS' WEAR CAUSED BY FRICTION TORQUE}

Testing of new construction concepts for improving hip prostheses were made by other authors. An attempt of a hip implant with tapered rolling elements is proposed by the Imperial College of Science, Technology and Medicine in London [4]. Another version, proposed by Katsutoshi Bekki and Kiyoshi Shinjo, includes a "train of balls" [5]. Another type of ball implant, with a "clearing space" allowing the rolling balls a free self-directioning movement is proposed by the Institute of Solid Mechanics, Romanian Academy, in collaboration with the University of Medicine and the University Hospital in Bucharest, Capitanu L., V. Florescu, Petrescu F., 2001 [6], [7].

In order to reduce the friction torque and extend the implant's lifetime, replacing the sliding friction with rolling friction was proposed. This will be achieved by inserting two ball-cages which replace the internal component made of polyethylene (Fig-5).

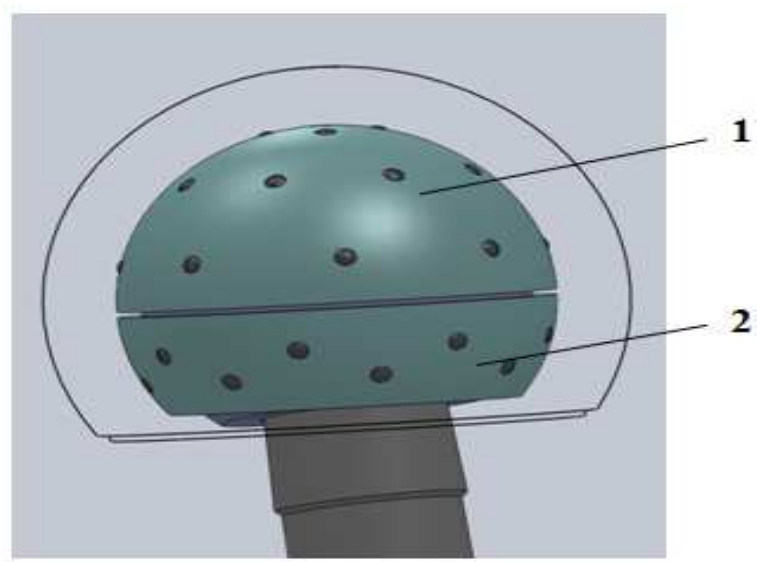

Fig5: The proposed low friction implant: 1-ball cage 1; 2- ball cage 2 
By inserting the two ball cages, a rolling friction occurs between the cup and the femoral head, which leads to a decrease in the friction coefficient. With the balls there occurs a point contact, the friction forces are reduced and the lifetime of the implant is extended.

In the rolling friction's case, due to elastic deformation, the contact takes place on surfaces that are small compared to the size of the rolling bodies. Tensions are called local contact stresses and they were first studied by Hertz on the following assumptions:

- Rolling bodies are homogeneous, isotropic and perfectly elastic

- The stress is maintained elastic all along

- The contact surface is very small compared to the size of the rolling bodies

- The force is perpendicular to the contact surface, so there are no tangential forces

- There is no lubricant between the surfaces and the contact surface is not flat, but flattened [8].

In the balls' case, this study applies as follows (Fig -6): the ball diameter was noted $\mathrm{db}$, the raceway radius was noted $\mathrm{rc}$ and the raceway's radii of curvature were noted $\mathrm{Ri}$ [8].

This area was calculated by Hertz
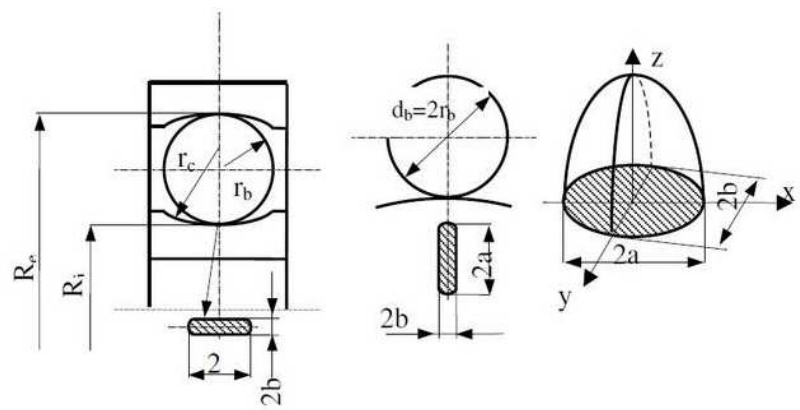

Fig -6: Study of the contact stresses in the balls' case [8]

The stresses are distributed spatially and take the form of an ellipsoid $(\sigma z)$

$$
\sigma_{z}=\frac{3}{2} \frac{F_{0}}{\pi_{a b}} \sqrt{1-\frac{x^{2}}{a^{2}}}-\frac{y^{2}}{b^{2}}
$$

For $\mathrm{x}=0, \mathrm{y}=0$ it results that $\sigma \mathrm{z} \max =\operatorname{pmax}=\frac{3}{2} \frac{F_{0}}{\pi a b}$

In the contact area there occur several unit stresses. If a point contact occurs, the stress distribution (normal unit stresses occurring on the contact surface) has an ellipsoidal shape [9].
For the prototype, two methods of building the ball cage are proposed (the metal outer cladding and the femoral head are used from a bipolar prosthesis).

A way of getting the balls into the cage is by flaring and reeling; with this method, the material for the cage is a piece of $316 \mathrm{~L}$ stainless steel sheet.

Metallic biomaterials are the most popular class of materials used for implants, prostheses and medical instruments, since they have very good mechanical properties; they are corrosion-resistant and acceptable in terms of biocompatibility. Metallic materials used as implant materials are those that are able to form passive stable protecting films on their surface, which "shut" the metal to the corrosive environment [10].

The steps in the process of making the ball cage are:

1) a disc-shape sample is cut from the $316 \mathrm{~L}$ steel sheet;

2) the resulting piece of steel is cupped;

3)the uneven edges are removed by trimming;

4) the semi-sphere is drilled using a dual indexing device (able to turn and index the piece); drilling is done on the outside;

5) a sand-blasting is performed in order to remove burrs;

6) the balls are fixed in the cage by flaring and reeling (pressing) with a figured tool. The fixing is done both on the outside and on the inside.

Table -1 shows the flow diagram for the ball cage flaring.

Table -1: Ball cage flow (by flaring and reeling)

\begin{tabular}{|l|l|l|}
\hline No. & Name & Sketch \\
\hline 1 & Stamping & Cupping \\
\hline 3 & Trimming (edges) & \\
\hline 4 & Drilling & Sanding is done \\
\hline 5 & Sand-blasting & remove burrs* \\
\hline
\end{tabular}




\begin{tabular}{|l|lll|}
\hline 6 & $\begin{array}{l}\text { Flaring on the } \\
\text { outside }\end{array}$ & Flaring on the inside \\
\hline 7 &
\end{tabular}

A second method of getting the balls into the cage is by pressing.

When this method is used, the cage is made of high density polyethylene.

This is commonly used for medical purposes due to its physical, chemical and mechanical properties.

Depending on the polymerization conditions, there are several types of polyethylene [11]:

-radical low density polyethylene (LDPE)
-linear low density polyethylene (LLDPE)
-high density polyethylene (HDPE)
-ultra-high-molecular-weight-polyethylene
(UHMWPE)

High density polyethylene (HDPE and UHMWPE) is used for orthopedic implants because of its good toughness and chemical stability, high resistance to impact, resistance to corrosive chemicals and non-toxicity.

UHMWPE has been used for over 40 years as a successful biomaterial for hip, knee and spine implants [12].

Polyethylene cages are made using an unconventional method, namely the deposition of successive layers of material, a technology known as Rapid Prototyping (RP).

The key principle of this new technology is based on decomposing the 3D model into thin cross-section layers, followed by the physical formation of layers and their "layer by layer" stacking. [13].

The cage was created using the SolidWorks software (Fig -7) and subsequently processed with NETFABB.

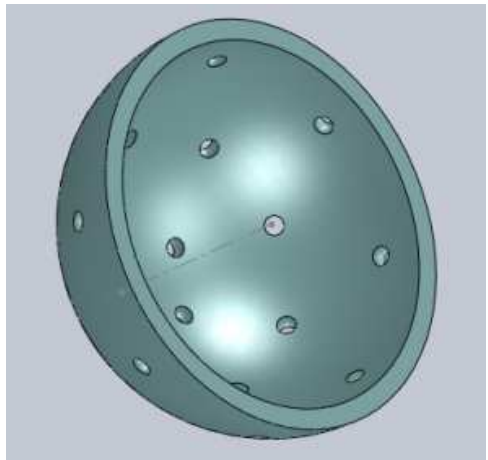

Fig -7: Solid Works image of cage 1

NETFABB is a software that performs the decomposition (mesharea) of the 3D model so it can be turned into a prototype (Fig -8).

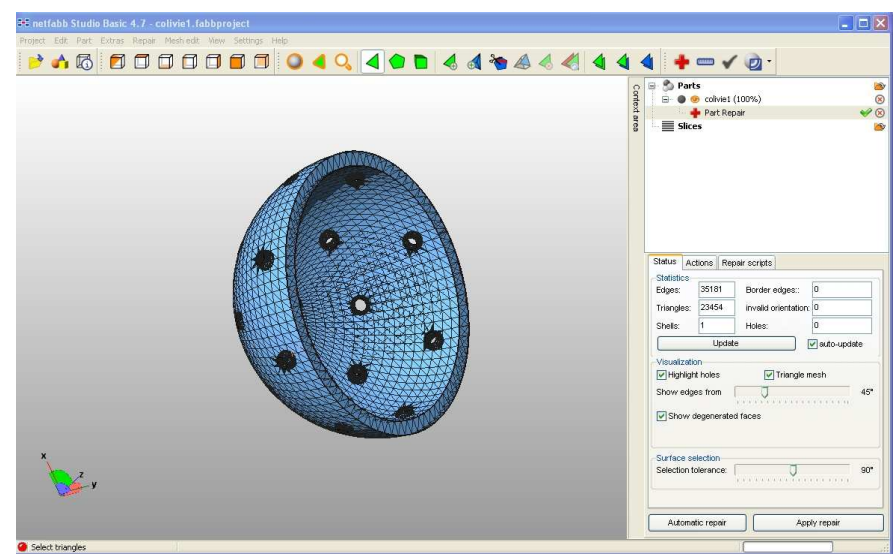

Fig -8: Cage 1 processed with NETFABB

For an easy examination of the three-dimensional model, additionally, a rapid generation of cage 1 is performed so that any potential design error can be detected and corrected before the high density polyethylene prototype is manufactured.

The cage is generated directly from the three-dimensional model with the Additive Layer Manufacturing (ALM) technology which uses thermoplastic filament for printing, with the help of the "BFB 3000 Plus"3D printer.

Before printing, the NETFABB-processed .stl file containing Cage 1 is imported in the AXON 2 software where it is converted into longitudinal sections (G.Code) ready for printing. The printer also is configured in the AXON 2. The printing is done as follows:

-the printer version is selected (BFB-3000 bed V2);

-the number of print heads is selected; 
-the type of material (ABS) used by the print head is selected (depending on the type of material, the printing temperature has to be adjusted);

-the thickness of the layer to be deposited is selected (the thinner the layer, the longer the time);

-the material for the rack and the material for the piece (if any) are selected;

-the fill level inside the cage is selected;

-the processing speed is selected (if the speed is high, the cage will not have enough time to cool and will be deformed)

-the cage is placed on the virtual printing bed; on opening the .stl file, the cage is set into an optimal position calculated by the program (minimum $\mathrm{Z}$ ); a better positioning is found by selecting the desired area that will form the base for the cage, so as to reduce the supporting area (which will be removed in the end); if the cage exceeds the workspace, a warning red cube will be displayed (Fig -9) and the cage will have to be moved until reaches inside the cube (the printing volume) and the warning red cube disappears.
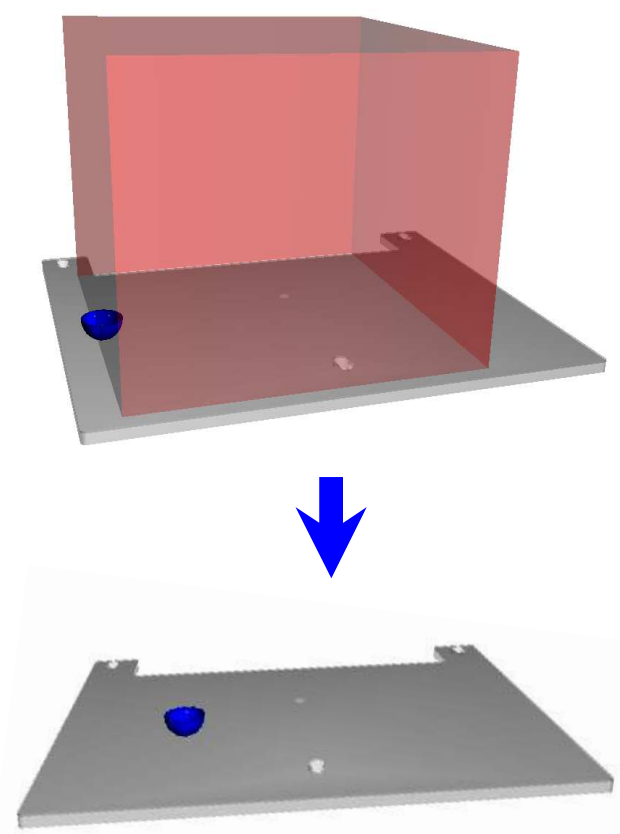

Fig -9: Cup exceeding the workspace

The part is sliced automatically and at the end of the process the estimated 3D print time, the cost, the volume extruded expressed in $\mathrm{cm} 3$ and the mass extruded expressed in grams are displayed. (Fig-10)

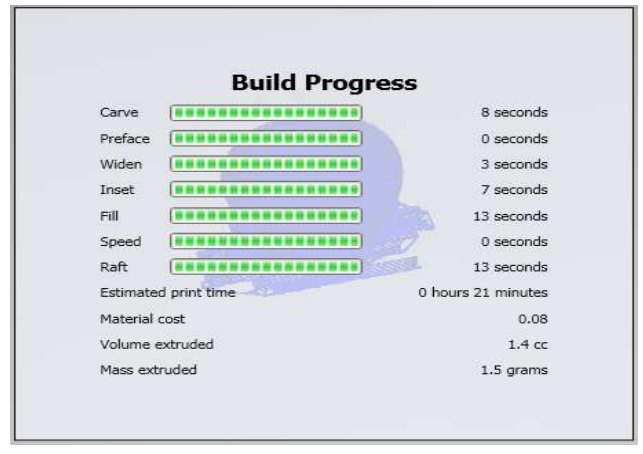

Fig -10: Cup slicing - process end statistics

The software-calculated cage positioning on the printing bed generates a print time of 21 minutes (Fig -9) and a large supporting base, which is created also inside the cage (Fig 11).

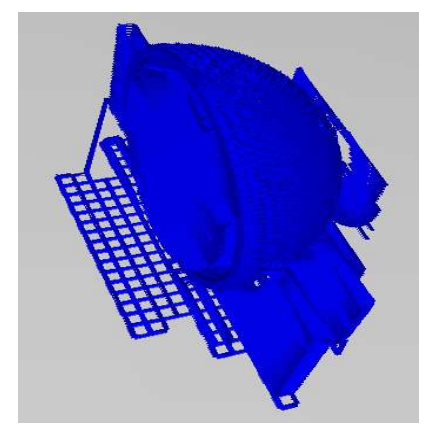

Fig -11: Software-generated positioning and supporting base of the cage

To create a smaller and more easily removed supporting base, the cup is repositioned.

After repositioning the cup, there resulted a print time of 15 minutes (Fig -12) and a smaller supporting base, while the supporting structure from inside the cage was removed. (Fig 13)

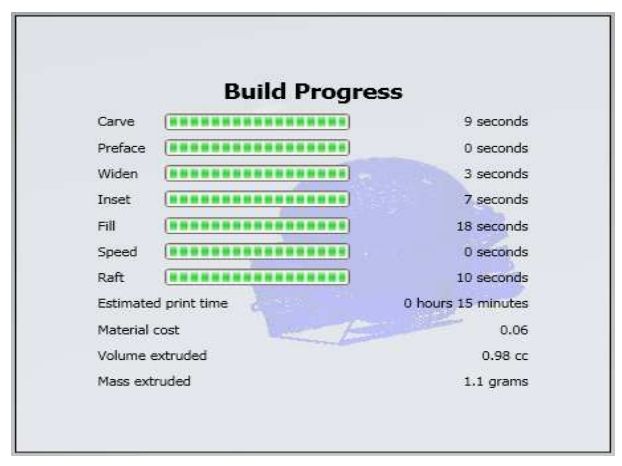

Fig -12: Cup slicing process after repositioning 




Fig -13: Supporting base resulting from the cup's repositioning.

Table -2 shows the flow diagram for the creation of ball cages by rapid prototyping.

Table -2: Ball cage flow (manufacturing by Rapid Prototyping)

\begin{tabular}{|c|c|c|}
\hline No. & Name & Sketch \\
\hline 1 & $\begin{array}{l}\text { 3D Design using the } \\
\text { SolidWorks software }\end{array}$ & \\
\hline 2 & $\begin{array}{l}\text { 3D processing using } \\
\text { the NETFABB } \\
\text { software (creating } \\
\text { the mesh area) }\end{array}$ & \\
\hline 3 & $\begin{array}{l}\text { Processing the file } \\
\text { using the AXON } 2 \\
\text { software and setting } \\
\text { the printing } \\
\text { parameters }\end{array}$ & \\
\hline & Printing the cage & \\
\hline 4 & & \\
\hline
\end{tabular}

\begin{tabular}{|c|c|c|}
\hline & & \\
5 & $\begin{array}{c}\text { Removing the } \\
\text { supporting base }\end{array}$ & $\begin{array}{c}\text { Mechanically or using } \\
\text { special solvents for ABS } \\
\text { material }\end{array}$ \\
\hline 6 & Fitting the ball & Performed by pressing \\
\hline
\end{tabular}

\section{CONCLUSIONS}

Although a great variety of implants have been created, their lifetime is actually lower than expected in theory due to the many causes that lead to the early wear of implants.

Due to the frictions that take place between the two components of the implant, there occurs the particlegeneration phenomenon, followed by the particles' reaching the tissues next to the implant. The polyethylene particle generation caused by wear is associated with intense cellular reactions leading to the shortening of the implant's lifetime. By replacing torque sliding friction with rolling friction we intend to reduce the wear of hip prostheses and the generation of particles caused by wear.

\section{REFERENCES}

[1]. Liliana-Laura Bădiţă Contribuţii privind îmbunătăţirea caracteristicilor tribologice ale protezelor de şold, prin nanodepuneri de materiale biocompatibile, pp.14 http://www.imsar.ro/Rezumat_teza_Badita.pdf (19.02.2013). [2].http://xa.yimg.com/kq/groups/31819573/1865311474/nam e/Trib_WEB_01_Clasificare+cuple+de+frecare.pdf (accessed on 17.05 .2013 )

[3].http://www.scribd.com/doc/13628742/BiotribologieCapit4 (accessed on 21.03.2013)

[4]. Sadeghi-Mehr, M., „Investigations of Rolling Element Bearing for Hip Joint Prosthesis", PhD Thesis, Imperial College of Science, Technology and Medicine University, London, 1977.

[5].Katsutoshi B., S. Kiyoshi, US Patent 5092898/30.03.1992 [6]. L. Capitanu, V. Florescu. „New Concepts for Improved Durability in MOM Total Hip Endoprostheses" A review. American Journal of Materials Science Vol.2, No. 6, December 2012, pp. 185-201

[7]. L. Capitanu, , Liliana Laura Badita, V. Florescu, Dumitru Catalin Bursuc ,Preliminary Study on the Seizure Trend of a MOM-Thp with Self-Directed Balls", 13th International Conference on Tribology - Serbiatrib'13; pp 331-340

[8].http://www.omtr.pub.ro/didactic/om isb.om2/om2.pdf (accessed on 10.07.2013) 
[9].http://www.scribd.com/doc/55566517/Material-CursIntroduce-Re-Biomateriale, (accessed on 11.10.2011)

[10].http://www.scribd.com/doc/55566517/Material-Curs-

Introduce-Re-Biomateriale, (accessed on 11.10.2011)

[11].http://www.revista-

informare.ro/showart.php?id=125\&rev=5 (accessed on 09.07.2013)

[12]. S. Mihai, V.Filip 3D Modeling and Performing of Orthopedic Implants by Material Deposition Rapid Prototyping, 2012 4th International Conference on Innovations, Recent Trends and Challenges in Mechatronics, Mechanical Engineering and New High-Tech Products Development

[13].http://ro.wikibooks.org/wiki/Artroplastia_total\%C4\%83 de_\%C5\%9Fold_primar\%C4\%83/evaluare_postoperatorie (accessed on 09.07.2013) 